\title{
Papel do capital social e das instituições no desenvolvimento econômico
}

\author{
Carolina Miranda Cavalcante ${ }^{1}$
}

\section{RESUMO}

Esse trabalho tem por objeto conceitos e teorias concernentes ao desenvolvimento econômico e social e os mecanismos para sua construção. São destacadas algumas categorias consideradas pela literatura como importantes para o desenvolvimento, como instituições, capital social, bem como a confiança, apontada como seu mecanismo de transmissão para políticas econômicas. O objetivo do presente trabalho é uma apresentação de alguns autores responsáveis pelas categorias acima mencionadas. No que tange à temática das instituições destaco a teoria institucionalista de Douglass North. Sobre capital social exponho a perspectiva de Robert Putnam. No que concerne à possibilidade da construção da confiança apresento o esquema analítico sugerido por Richard Locke.

Palavras-chave: instituições, capital social, confiança, desenvolvimento, economia institucional.

\section{The role of social capital and institutions in economic development}

\begin{abstract}
The scope of this article embraces concepts and theories concerned with social and economic development as well as the mechanisms for their construction. Some categories considered by the literature as important to development are chosen, they are: institutions, social capital and trust. The concept of trust is important because it is recognized as the mechanism through which social capital can effectively participate in economic policy. This article aims to sketch the concepts and theories developed by the authors above mentioned. In which concerns institutions, the institutionalism of Douglass North will be presented. From the case studies by Robert Putnam it is selected the idea of social capital to be worked on. About the possibility of the construction of trust the theoretical approach by Richard Locke will be considered.
\end{abstract}

Keywords: institutions, social capital, trust, development, institutionalism.

\section{INTRODUÇÃO}

$\mathrm{Na}$ definição fornecida por North, instituições são as regras do jogo de uma sociedade, regras essas que podem ser formais ou informais. As regras formais podem ser controladas e mantidas de forma mais direta pelo Estado, que pode agir sobre as legislações que regem o comportamento das firmas e dos indivíduos. $\mathrm{O}$ instrumento utilizado pelo Estado em última instância para garantir as regras formais é o uso do seu poder de polícia. As regras informais são códigos de conduta não escritos e seguidos tacitamente pelos indivíduos. A manutenção das regras informais depende basicamente do monitoramento e dos instrumentos

\footnotetext{
${ }^{1}$ Professora de Economia Política e Economia Institucional do Departamento de Direito Social e Econômico da Faculdade Nacional de Direito da UFRJ. Possui graduação, mestrado e doutorado em Ciências Econômicas pela UFF. As áreas de interesse e pesquisa compreendem os debates em Filosofia da Ciência e Economia Institucional. E-mail: cmcavalcante@gmail.com
} 
de punição do grupo no qual o indivíduo encontra-se inserido, instrumentos esses que normalmente consistem em exclusão ou afastamento da rede de relacionamentos estabelecida entre os membros do grupo.

Quando definidas dessa forma, as instituições são entendidas como fornecedoras de incentivos para a tomada de decisão dos indivíduos. Nesse sentido, instituições que fornecem incentivos à aquisição de habilidades produtivas originarão economias prósperas, enquanto instituições que incentivam a pirataria darão origem a economias pouco desenvolvidas. A promoção do desenvolvimento fica condicionada à existência dessas "boas instituições" incentivadoras da aquisição de habilidades produtivas. Contudo, é apontado que essas "boas instituições" podem não ter precedido o nível de desenvolvimento alcançado pelas atuais economias mais ricas.

Dois problemas se apresentam: um teórico e outro prático. O problema teórico diz respeito ao sentido da causalidade, a saber, são as instituições que são responsáveis pelo desenvolvimento econômico ou é a partir de um dado nível de desenvolvimento econômico que essas "boas instituições" adquirem a possibilidade de emergir? Se escolhermos a primeira alternativa algumas evidências históricas refutam nossa tese, mas se recorremos à segunda alternativa nos deparamos com um problema prático, a saber, a ausência de um modelo para a promoção de políticas que engendrem o desenvolvimento de regiões pouco desenvolvidas e carentes dessas "boas instituições".

Talvez uma resposta para essas questões esteja na aceitação das duas possibilidades teóricas. Podemos reconhecer que, em alguns casos, a observação histórica nos mostra que é preciso algum nível de desenvolvimento que forneça as bases para que essas "boas instituições" possam emergir; contudo, resta saber o que exatamente estamos entendendo pelo mencionado nível de desenvolvimento e que instituições são essas. Este pode estar relacionado aos tradicionais indicadores macroeconômicos ou a aspectos mais sociológicos como cultura, religião e demais formas de interação social, ou ainda à forma como essas duas dimensões da vida social se inter-relacionam. Ademais, se pretendemos interferir no curso da atividade econômica e, desta maneira, mudar seu rumo é essencial que concebamos políticas que visem reconduzir a forma como as pessoas se comportam em suas atividades produtivas. Isso nos remete ao outro sentido da causalidade, isto é, aquele no qual mudanças nas instituições formais são capazes de afetar o nível de desenvolvimento de uma sociedade.

Interferir no modo como as pessoas se comportam passa pela alteração das formas de interação desses indivíduos, interação essa regida por regras formais e informais, ou seja, por 
instituições. Uma compreensão mais ampla das instituições, para além da sua dimensão formal, pode nos dar alguns insights acerca de como proceder no sentido de alterar o curso da atividade econômica. Alguns autores chamam a atenção para a categoria do capital social, que responde pelas características e pelo grau de organização social de uma dada comunidade. Nessa literatura a confiança emerge como um mecanismo através do qual o capital social se converte em desempenho institucional. Isso nos permite entender as políticas de promoção do desenvolvimento não apenas como modificações nas regras formais, mas também como ações direcionadas ao aumento do engajamento da população nos programas do governo através de ações que incentivem a organização comunitária em prol de um objetivo que seja comum a todos os membros da comunidade.

Deste modo, apresento algumas soluções propostas pela literatura sobre capital social e instituições no que concerne às modalidades de políticas direcionadas à promoção do desenvolvimento em regiões carentes tanto de "boas instituições" quanto de uma cultura de confiança e associativismo. Deve-se acrescentar, são regiões que provavelmente apresentam níveis reduzidos de desenvolvimento econômico.

Esse artigo possui, além dessa Introdução e da Conclusão, três itens. O primeiro item trata do conceito de instituição sugerido por Douglass North, bem como de sua compreensão do papel das instituições no desenvolvimento econômico. No segundo item apresento o conceito de capital social tal como sugerido por Robert Putnam, bem como os mecanismos para a construção da confiança conforme apresentado por Richard Locke. No terceiro item realizo algumas considerações acerca da relação entre instituições, capital social e desenvolvimento.

\section{DEFININDO INSTITUIÇÕES: DAS SUAS DIMENSÕES FORMAL E INFORMAL}

Nesse item, apresento o papel das instituições no desenvolvimento econômico tal como compreendido por Douglass North ${ }^{2}$, um dos autores responsáveis pelas ideias seminais da nova economia institucional, ao lado de Ronald Coase e Oliver Williamson. Segundo o autor, as instituições podem ser divididas em duas dimensões: a formal, que são as leis impostas pelo Estado e a informal, que compreende o conjunto de regras estabelecido pelos indivíduos e que emerge de sua interação em sociedade. $\mathrm{O}$ autor destaca como medida de

\footnotetext{
${ }^{2}$ Este item está baseado em North $(1981 ; 1990)$. Outras referências são indicadas ao longo do texto.
} 
desenvolvimento econômico indicadores como produto total, produto per capita e distribuição de renda.

North tem como objetivo explicar a estrutura e a performance das economias ao longo do tempo. Nesse sentido, propõe que uma noção de evolução institucional seja incorporada ao arcabouço teórico neoclássico. Para tal faz-se necessária a adoção de um conceito de racionalidade limitada, a inserção da dimensão temporal, mas com a manutenção do suposto de escassez de recursos.

Inicialmente é preciso expor como se compõe a estrutura do sistema econômico, conforme delineado por North. $\mathrm{O}$ ambiente econômico pode ser entendido como o tabuleiro no qual acontece o jogo econômico, dado pela interação entre indivíduos e organizações, cujas regras são estabelecidas pelo Estado (restrições formais) e pelos códigos de conduta não oficialmente sancionados pelo Estado (restrições informais). O ambiente econômico é composto por recursos escassos, bem como se encontra inserido no tempo, de modo que as ações passadas constituem as restrições e possibilidades apresentadas no momento presente, no qual os agentes tomam suas decisões.

Os jogadores do sistema econômico são os indivíduos e as organizações. Indivíduos são agentes dotados de racionalidade limitada, definida por Herbert Simon como o termo "usado para designar escolha racional que leva em consideração as limitações cognitivas do agente que toma decisões - limitações tanto do conhecimento quanto da capacidade computacional” (SIMON, s.d., p.15). Os indivíduos são ainda capazes de agir intencionalmente, formulando concepções relativas ao funcionamento do sistema econômico; são, portanto, agentes estratégicos e dotados de capacidade, ainda que limitada, de ação e planejamento. As organizações são compostas por indivíduos com propósitos comuns, que se reúnem em organizações no intuito de reduzir os custos de transação envolvidos nas trocas realizadas no sistema econômico. Alguns exemplos de organização são: firmas, igrejas, clubes, universidades, organizações não governamentais, etc. Em resumo, uma organização é qualquer grupo, de caráter público ou privado, de indivíduos que possuem um objetivo comum, sendo regido por um conjunto de regras formais e/ou informais, bem como por alguma estrutura hierárquica. A eficiência dessa organização será dada pela sua capacidade de reduzir os custos de transação presentes no sistema econômico ${ }^{3}$.

\footnotetext{
${ }^{3}$ Segundo Coase (1990 [1937]), os custos de transação originam-se dos custos inerentes ao uso do mecanismo de preços. Emerge daí a razão pela qual as firmas e o Estado, além do mercado, existem como mecanismos alternativos de alocação de recursos.
} 
As regras do jogo econômico possuem duas dimensões: a formal e a informal. Essas regras têm por função fornecer um conjunto de parâmetros para a tomada de decisão dos jogadores - indivíduos e organizações -, além de constituírem restrições à ação individual. North define restrições formais como "as regras codificadas que as pessoas concebem, como leis e constituições, e as restrições informais como convenções e códigos de conduta auto impostos pelos indivíduos" (NORTH, 1990, p. 4).

Instituições são as regras do jogo numa sociedade, ou mais formalmente, são as restrições humanamente criadas que moldam a interação humana. Em consequência elas estruturam os incentivos na troca humana, seja política, social ou econômica. A mudança institucional molda a maneira como as sociedades evoluem ao longo do tempo e, portanto, é a chave para a compreensão da mudança histórica (NORTH, 1990, p. 3) 4 .

As leis e as constituições comportam elementos como contratos e direitos de propriedade, responsáveis pela regulação das trocas econômicas realizadas entre indivíduos e entre organizações. O Estado especifica e garante os direitos de propriedade através do uso exclusivo da força, sendo "responsável pela eficiência da estrutura de direitos de propriedade, que induzem ao crescimento ou à estagnação ou ao declínio econômico" (NORTH, 1981, p. 17). As restrições informais emergem da interação entre os jogadores, sendo moldadas por fatores culturais, demográficos e religiosos cristalizados ao longo do tempo nos grupos sociais. North destaca a ideologia como uma categoria mais geral componente das restrições informais, consistindo nas concepções que os indivíduos possuem acerca do sistema econômico.

Por ideologia entendo as percepções subjetivas (modelos, teorias) que todas as pessoas possuem para explicar o mundo à sua volta. Seja no nível micro dos relacionamentos individuais seja no nível macro das ideologias organizadas provedoras de explicações integradas do passado e do presente, como o comunismo ou as religiões, as teorias que os indivíduos constroem são coloridas por visões normativas de como o mundo deve ser organizado (NORTH, 1990, p. 23) ${ }^{5}$.

Deste modo, a estrutura econômica compreende quatro elementos básicos além de seus jogadores: instituições, ideologia, demografia e tecnologia. Vimos que as instituições fornecem as regras - formais e informais - do jogo econômico; a ideologia converte-se numa restrição auxiliar, poupadora de custos de monitoramento quando os indivíduos compreendem

\footnotetext{
4 "Institutions are the rules of the game in a society or, more formally, are the humanly devised constraints that shape human interaction. In consequence they structure incentives in human exchange, whether political, social, or economic. Institutional change shapes the way societies evolve through time and hence is the key to understanding historical change" (North, 1990, p.3).

5 "By ideology I mean the subjective perceptions (models, theories) all people possess to explain the world around them. Whether at the microlevel of individual relationships or at the macrolevel of organized ideologies providing integrated explanations of the past and the present, such as communism or religions, the theories individuals construct are colored by normative views of how the world should be organized" (North, 1990, p.23).
} 
o sistema econômico como justo. Segundo North (2005a; 2005b), os fatores demográficos são importantes na medida em que teriam moldado ao longo do tempo as crenças culturais e religiosas responsáveis pela armação institucional das sociedades. A tecnologia é definida como o controle humano sobre a natureza, respondendo pela dotação de recursos naturais, capital físico e capital humano de uma economia. O controle do homem sobre o meio natural depende de uma variável ainda não mencionada, o aprendizado. North destaca que é importante observar tanto o tipo quanto a taxa de aprendizado. O tipo de aprendizado no qual os jogadores vão investir seu tempo é determinado pelos incentivos fornecidos pela matriz institucional, enquanto a taxa de aprendizado dependerá da velocidade com que esses jogadores são capazes de assimilar novas informações e de se adaptar às mudanças ocorridas no sistema econômico.

Uma vez explicitada a natureza do sistema econômico e a modalidade de ação de seus jogadores, torna-se necessário mencionar os indicadores que North estabelece para medir a performance desse sistema econômico. $\mathrm{O}$ autor menciona basicamente três indicadores de performance econômica, são eles: produto total, produto per capita e distribuição de renda. Embora exista, no arcabouço conceitual de North, a possibilidade teórica de medição dos resultados da atividade econômica para além da esfera estritamente econômica, o autor menciona apenas os tradicionais indicadores de performance econômica. Todavia, se reconhece a necessidade e a tentativa de construção de indicadores de medição da atividade econômica que considerem fatores que transcendam a esfera estritamente econômica. No item quarto, menciono algumas de ideias de Amartya Sen, outro autor preocupado com as temáticas concernentes ao desenvolvimento econômico.

\section{CAPITAL SOCIAL E CONFIANÇA}

Os escritos seminais concernentes ao conceito de capital social podem ser identificados nos trabalhos de Robert Putnam, James Coleman e Pierre Bourdieu das décadas de 1980 e 1990. O capital social assume várias formas - como confiança, normas e cadeias de relações sociais -, que funcionam como mecanismos através dos quais o capital social se torna capaz de incrementar o desempenho institucional. Nesse sentido, o capital social responde, ao menos em parte, pelo desempenho institucional das economias.

North destacara a importância das instituições no fornecimento de um sistema de incentivos responsável pela orientação dos indivíduos em seu processo de tomada de decisão. 
A escolha dos agentes em relação ao tipo de habilidades a ser adquirida, se voltadas para atividades produtivas ou não, dependeria dos incentivos fornecidos pela matriz institucional. Desta forma, a dotação de capital humano de uma sociedade estaria diretamente ligada ao seu arcabouço institucional. As instituições importam no esquema conceitual de North porque fornecem os parâmetros para a tomada de decisão individual, determinando o tipo de habilidade adquirida pelos indivíduos (capital humano), responsável, por sua vez, pelo grau de controle humano sobre a natureza (tecnologia), que, por fim, determinaria o nível de produto total da economia (nível de crescimento econômico). O autor deixa, contudo, à margem de sua análise elementos outros não diretamente ligados à atividade econômica, mas que certamente a influenciam.

Ao inserir o conceito de ideologia, North abre espaço para o questionamento da existência de outros mecanismos de monitoramento e coerção para além dos tradicionais instrumentos de manutenção das regras formais utilizadas pelo Estado. Uma pergunta pertinente, afirma North, é: por que alguns indivíduos, em determinadas situações, não burlam as regras estabelecidas mesmo na ausência de monitoramento e possibilidade de punição? Por que não jogar lixo no chão mesmo quando não tem ninguém olhando? Por que não roubar se inexiste o risco de punição? A explicação fornecida por North é a de que na medida em que os indivíduos percebem o sistema econômico como justo, as regras estabelecidas são por eles assimiladas e os próprios agentes passam a se auto monitorar. A decisão de não burlar as regras passa a ser mais uma questão moral (é errado jogar lixo no chão, é errado roubar) do que um temor com relação a uma possível punição (multa, detenção).

Embora o esquema conceitual de North ofereça uma gama de possibilidades teóricas, a dimensão política das instituições não emerge tão explicitamente. A categoria da ideologia explica o comportamento individual que se autopolicia, ajudando assim na manutenção das regras sociais, mas nos informa de forma vaga acerca da origem desse comportamento ao identificá-la de modo genérico com a herança cultural das sociedades. Por que em algumas economias os indivíduos percebem o sistema como justo e em outras não? Que propriedades possuem essas sociedades que fornecem aos agentes uma concepção das instituições como confiáveis? Fazer o que é certo depende, em certa medida, da expectativa acerca de como os outros irão se comportar, visto que pode ser perfeitamente racional não cooperar em determinadas situações. São os dilemas da ação coletiva, que impedem que indivíduos racionais hajam de modo cooperativo, sob pena de incorrerem em prejuízos privados. 
Duas formas de superação dos dilemas da ação coletiva são: a coerção de um terceiro (Estado) ou a cooperação voluntária. O problema com a aplicação dos instrumentos de controle e coerção do Estado são os custos do uso do poder de polícia e a inexistência de imparcialidade dos agentes do Estado, ou seja, os indivíduos que controlam o Estado também seriam dotados de autointeresse. A cooperação voluntária dependerá do capital social presente em determinada sociedade, que por sua vez responderá pela acumulação de capital institucional (PUTNAM, 2007, p. 179). Ademais, Putnam (2007) destaca que as instituições são mecanismos para alcançar propósitos, não apenas acordo, e que se espera que o governo faça coisas, não apenas decida coisas. Destarte, se desejamos transformar as instituições em mecanismos de promoção do desenvolvimento econômico, faz-se necessário entender os determinantes do desempenho institucional. Nesse propósito exponho a seguir os pontos centrais da tese de Putnam acerca do papel do capital social no desempenho institucional e, em seguida, os mecanismos destacados por Locke como necessários para a construção da confiança em regiões carentes do estoque de capital social adequado ao desenvolvimento de instituições eficientes.

\subsection{O papel do capital social no desempenho institucional}

Putnam (2007) tem por objetivo compreender o desempenho das instituições democráticas, buscando entender a influência das instituições formais nas práticas da política e do governo. Sua obra tem como base o estudo do impacto da descentralização administrativa ocorrida na década de 1970 no Norte e no Sul da Itália. Ao observar o bom desempenho institucional no Norte e a presença de práticas clientelistas e o mau desempenho institucional do Sul, o autor questiona sobre as condições necessárias para a criação de instituições fortes, responsáveis e eficazes.

Em acordo com os institucionalistas, Putnam destaca o duplo papel das instituições: i) as instituições moldam a política, influenciando os resultados porque moldam a identidade, o poder e a estratégia dos atores; e ii) as instituições são moldadas pela história, em que os indivíduos podem "escolher" suas instituições, mas não o fazem em circunstâncias que eles mesmos criaram, e suas escolhas, por sua vez, influenciam as regras dentro das quais seus sucessores fazem suas escolhas (PUTNAM, 2007, p. 23). Ademais, o desempenho prático das instituições é moldado pelo contexto social em que atuam (PUTNAM, 2007, p. 24). Deste modo, se por um lado a mudança institucional tem como objetivo a remodelação da vida 
política, produzindo assim impactos econômicos, por outro lado a mudança nas instituições presentes encontra como restrição a história herdada e o contexto social no qual estão inseridas.

O legado cultural de uma sociedade pode inseri-la em duas dinâmicas distintas, num círculo virtuoso, em que confiança e cooperação se auto reforçam, ou num círculo vicioso, em que a desconfiança entre os agentes e destes em relação às instituições gera um cenário no qual é racional não cooperar. Confiança, contudo, não necessariamente tem a ver com comportamento ingênuo ou altruísta, visto que a "confiança necessária para fomentar a cooperação não é uma confiança cega. A confiança implica uma previsão do comportamento de um ator independente" (PUTNAM, 2007, p.180). Nesse sentido, confiança tem mais a ver com comportamento estratégico do que com comportamento altruísta. As regras da confiança social a fortalecem através da redução dos custos de transação e da facilitação da cooperação (PUTNAM, 2007, p.181). A questão que se coloca é: como passar da confiança pessoal para a confiança social? A confiança pessoal é mais comum em pequenos grupos, que são mais coesos e caracterizados por laços fortes, enquanto a confiança social está mais ligada a grupos mais dispersos, caracterizados por laços fracos e pela presença mais evidente do comportamento auto interessado ${ }^{6}$.

Putnam menciona duas fontes de confiança social: as regras de reciprocidade e os sistemas de participação cívica. A reciprocidade é um componente altamente produtivo do capital social, combinando altruísmo no curto prazo com interesse próprio no longo prazo (PUTNAM, 2007, p.182). Inspirado na ideia de enraizamento social de Granovetter (1973; 1982), Putnam assinala que a combinação entre ordem/cooperação e desordem/oportunismo numa sociedade dependerá dos intercâmbios sociais preexistentes, como sistemas de relacionamento horizontais ou verticais, bem como a presença e a modalidade de regras formais e/ou informais.

Segundo Putnam (2007, p.30-31), uma comunidade cívica caracteriza-se por cidadãos atuantes e imbuídos de espírito público, por relações políticas igualitárias e por uma estrutura social firmada na confiança e na colaboração. "A consciência que cada um tem de seu papel e de seus deveres como cidadão, aliada ao compromisso com a igualdade política, constitui o cimento da comunidade cívica" (PUTNAM, 2007, p.192). Quanto mais desenvolvidos os sistemas de participação cívica, mais cooperação é obtida na interação social. As razões para isso consistem no fato de que em comunidades cívicas: $i$ ) existem

\footnotetext{
${ }^{6}$ Sobre o conceito de laços fracos e laços fortes ver Granovetter $(1973 ; 1982)$.
} 
maiores custos potenciais para o transgressor das regras sociais; ii) estão presentes sólidas regras de reciprocidade; iii) a comunicação é facilitada, melhorando o fluxo de informações sobre a confiabilidade dos indivíduos, reduzindo a incerteza; e iv) corporifica êxitos anteriores, criando um modelo culturalmente definido para futuras colaborações, ou seja, gera rotinas para solução de problemas.

Se pelo lado da demanda os cidadãos querem um bom governo, pelo lado da oferta o desempenho do governo é influenciado pela infraestrutura social das comunidades cívicas e pelos valores democráticos das autoridades e dos cidadãos (PUTNAM, 2007, p.191-192). A diferença entre as diversas comunidades é que nas mais cívicas os cidadãos exigem serviços públicos mais eficazes, se associando para atingir objetivos comuns, enquanto nas menos cívicas os cidadãos "assumem o papel de suplicantes cínicos e alienados" (PUTNAM, 2007, p.191). Observa-se, portanto, um caminho de mão dupla entre o desempenho do governo e a qualidade dos cidadãos, de modo que uma vez iniciada uma dinâmica, de cooperação ou não cooperação, esta tende a se perpetuar. Enquanto as associações cívicas "reforçam os 'hábitos do coração' que são essenciais às instituições democráticas estáveis e eficazes" (PUTNAM, 2007, p.27), a ausência de uma cultura cívica gera um círculo vicioso em que "por reagirem racionalmente ao contexto social que lhes foi legado pela história, os indivíduos acabam reforçando as patologias sociais" (PUTNAM, 2007, p.188).

Diante do exposto, pode parecer desanimador e até mesmo inócuo qualquer esforço no sentido da elaboração de políticas voltadas ao incremento da qualidade das instituições e do desenvolvimento econômico. Contudo, Putnam (2007, p.191-193) destaca três lições retiradas da análise da experiência italiana: i) o contexto social e a história condicionam profundamente o desempenho das instituições; ii) mudando-se as instituições formais pode-se mudar a prática política; e iii) a história institucional costuma evoluir lentamente. O trabalho de Putnam explicita os caminhos seguidos pela história institucional do Norte e do Sul da Itália, apontando que, nesse caso específico, a presença de uma cultura cívica foi mais importante do que os níveis iniciais de desenvolvimento socioeconômico de tais regiões no que concerne ao seu atual desempenho institucional. Conhecidas as causas do atraso institucional, nos resta entender como reverter um círculo vicioso de desconfiança num círculo virtuoso de confiança nas instituições. Em outras palavras, como estimular o surgimento de uma cultura de associativismo em regiões com mau desempenho institucional? O trabalho de Richard Locke sobre a construção da confiança em regiões nas quais ela não está presente pode nos ajudar a iluminar essa questão. 


\subsection{Confiança: o elo entre capital social e desempenho institucional}

A partir do que foi apresentado acerca das potencialidades do capital social no que concerne ao incremento do desempenho institucional e ao desenvolvimento econômico, podemos agora explicitar um dos mecanismos através do qual o capital social se converte em instrumento de política econômica, a confiança.

Segundo Locke (2003), fatores como o capital social, o associativismo e algumas instituições-chave são responsáveis pela promoção da confiança, que por sua vez é importante para a prosperidade econômica, para o desenvolvimento econômico e para a eficiência dos arranjos organizacionais internos e entre firmas. A confiança é, portanto, um elemento importante para o desempenho das economias, mas não está presente em todas as economias. Sendo assim, a confiança pode ser criada? Se a confiança pode ser criada, então como fazer com que ela surja em localidades nas quais não se encontra presente?

Locke identifica duas visões acerca da confiança. A visão sociológica entenderia confiança como "um produto de longo prazo de padrões históricos de associativismo, compromisso cívico e interações extrafamiliares" (LOCKE, 2001, p.254). A partir dessa perspectiva, quanto mais confiança e cultura de associativismo possuir uma sociedade, maior será sua performance institucional e econômica. De acordo com a visão econômica é o interesse próprio que leva os indivíduos a cooperar uns com os outros, posto que em determinadas situações torna-se racional cooperar. Nesse sentido, "a cooperação e o comportamento confiável [trust-like behavior] - longe de serem um artifício cultural - são uma resposta racional de atores individuais ao conjunto de oportunidades e limitações presentes em seu ambiente" (LOCKE, 2001, p.256). Locke busca reunir essas duas visões sobre confiança observadas na literatura em uma abordagem que supere suas deficiências ${ }^{7}$, adotando a definição de confiança de Gambetta:

[...] os atores econômicos manifestam confiança quando, em situações de informação incompleta e incerteza (...), estes atores expõem-se apesar disso ao risco de comportamento oportunista porque têm razões para acreditar que os outros atores não tirarão proveito dessa oportunidade (LOCKE, 2001, p.259).

Locke afirma, a partir do estudo do Sul da Itália e do Nordeste do Brasil, ser possível construir a confiança, mencionando três fatores que a promovem e a sustentam: i) interesse próprio; ii) instituições; iii) organização da sociedade civil. A construção da confiança é

\footnotetext{
7 Segundo Locke (2001, p.257-258) são três as limitações da literatura sobre confiança: esta seria estática, mecanicista e pessimista.
} 
entendida como um processo sequencial que combina desenvolvimento de mecanismos de auto governança nas associações que garantam a estabilidade e a longevidade dos esforços cooperativos, participação ativa da política governamental e monitoramento pelos próprios agentes. A base de todo o processo de construção da confiança é o interesse próprio, capaz de suscitar o comportamento confiável entre os indivíduos caso a alternativa racional seja a cooperação.

Como forma de sustentar seu argumento, Locke (2003) menciona dois estudos de caso, um realizado entre os produtores de mozzarella de búfala no Sul da Itália e outro realizado entre os produtores e exportadores de uva de mesa e manga no Nordeste do Brasil. No caso brasileiro é destacado o papel da iniciativa de quatro dos maiores produtores de Petrolina-Juazeiro - fronteira de Pernambuco com a Bahia -, que se associaram na década de 1980 formando a Valexport como resposta à crise no mercado de melões ocorrida nessa década. O governo interveio fornecendo apoio a Valexport em troca do seu compromisso no sentido de abrir a associação para todos os produtores que desejassem dela participar. No ano da pesquisa de Locke (2003), a Valexport agregava cerca de 200 produtores de diversos tamanhos, sendo a região de Petrolina-Juazeiro responsável por $90 \%$ das exportações de manga e $30 \%$ das exportações de uva de mesa do Brasil.

O que o caso de Petrolina-Juazeiro ilustra, assim como o do Sul da Itália, é que a confiança pode emergir em regiões marcadas pela pobreza, pelo mau desempenho institucional e pela falta de uma comunidade cívica. Para a construção da confiança destaca-se em primeiro lugar a iniciativa de indivíduos e firmas, cujo interesse próprio faz com que cooperem em associações locais. Num segundo momento é essencial a participação do governo, apoiando e monitorando as associações assim criadas. Contudo, interesse próprio e intervenção governamental não são suficientes, posto que é ainda necessário construir mecanismos autopoliciadores no âmbito das associações e instituições criadas, de modo a garantir a estabilidade e longevidade dos esforços associativos.

\section{DESENVOLVIMENTO E INSTITUIÇÕES: DO SENTIDO DA CAUSALIDADE}

Ao se tratar de desenvolvimento econômico é possível pensar em duas de suas dimensões, a saber, crescimento do produto e qualidade das instituições. Pode-se argumentar que crescimento econômico e instituições de qualidade andam juntos. Contudo, existem casos 
nos quais é possível observar um descompasso entre essas duas dimensões do desenvolvimento econômico.

North (2005b), por exemplo, reconhece que no caso da China taxas de crescimento elevadas são obtidas sem que estejam presentes instituições nos moldes das norte-americanas, apontadas pelo autor como as mais eficientes. Chang (2004), por sua vez, assinala que nem sempre as instituições eficientes precedem o desenvolvimento econômico. Instituições eficientes são entendidas como aquelas presentes nos países desenvolvidos, principalmente nos anglo-saxões, compreendendo "a democracia, a burocracia 'boa', o Judiciário independente, a forte proteção aos direitos de propriedade privada (inclusive a intelectual) e uma governança empresarial, transparente e orientada para o mercado, assim como instituições financeiras (inclusive um banco central politicamente independente)" (CHANG, 2004, p.12). Em seu estudo da história de países atualmente desenvolvidos - como Estados Unidos, Grã-Bretanha, Alemanha, França, Suécia, Bélgica, Holanda, Suíça e Japão -, Chang constata que em alguma medida não apenas foram utilizadas políticas de proteção à indústria nascente, mas também as boas instituições acima mencionadas não estavam presentes.

A partir das observações de Chang, não se deve concluir que a adoção das referidas instituições é indesejável ou inócua, todavia é preciso assinalar o fato de que não é tão simples e imediato alcançar altos níveis de desenvolvimento econômico apenas com a criação de regras formais pelo Estado. Uma dimensão importante das instituições deve ser levada em consideração, a saber, a das regras informais, moldadas na interação individual; interação essa embebida em redes de relacionamento - como cultura, religião, família, clubes, associações, etc. - sendo ainda historicamente condicionada.

O estudo do caso italiano realizado por Putnam (2007) é ilustrativo da insuficiência de políticas unicamente direcionadas à provisão de recursos econômicos destinados à promoção do desenvolvimento econômico. $\mathrm{O}$ autor avalia o desempenho institucional antes e depois de sua implementação na década de 1970, em que foram instituídos os governos regionais no Sul e no Norte da Itália. Nesse estudo, Putnam verificou que embora essas duas grandes regiões tivessem um volume de recursos econômicos idênticos na época dessas transformações, seu desempenho institucional foi bastante diferenciado. Enquanto no Norte foi possível observar um bom desempenho institucional, no Sul italiano esse desempenho foi insuficiente, reforçando a descrença dos cidadãos em suas instituições. A explicação para esse fato, segundo Putnam, é a presença de uma cultura de associativismo, bem como uma cultura 
cívica de confiança nos cidadãos e nas instituições, presente no Norte e ausente no Sul italiano.

Deste modo, o sentido da causalidade entre instituições e desenvolvimento ocorre de forma dinâmica ao longo da história das sociedades, sendo possível em alguns casos identificar configurações específicas, capazes de nos informar o que foi inicialmente estabelecido, se reformas institucionais ou crescimento econômico. A identificação da origem dos atuais níveis de desenvolvimento econômico é objeto da pesquisa histórica, bastante útil na indicação de possíveis caminhos de política econômica. Contudo, a implementação dessas políticas depende de instrumentos que transcendem o recurso à história, posto que tais políticas se destinam à remodelação das configurações institucionais existentes. Assim sendo, caso o objetivo seja a elaboração de estudos voltados à proposição de políticas para o desenvolvimento econômico, é prudente a utilização não apenas de estudos de caso historicamente fundamentados, mas também de estudos estatísticos e etnográficos aliados à uma abordagem interdisciplinar do objeto social sob análise.

Além disso, vimos que as instituições possuem uma dimensão formal, diretamente controlada pelo Estado, e uma dimensão informal, que emerge da interação individual e é controlada indiretamente pelo Estado. O sucesso das políticas econômicas dependerá da relação entre essas duas dimensões institucionais, isto é, da compatibilidade entre as leis e as regulamentações impostas pelo Estado e os códigos de conduta estabelecidos na interação individual. Não basta simplesmente instituir regras, estas devem ser compatíveis com a visão de mundo dos agentes, que por estar inserida em contextos sociais específicos, dificultam e até impossibilitam a formulação de políticas de desenvolvimento padronizadas a serem aplicadas em diferentes sociedades. Destarte, assim como "um indivíduo pode definir e defender seus interesses diferentemente em diferentes contextos institucionais, também uma instituição formal pode atuar diferentemente em diferentes contextos" (PUTNAM, 2007, p.24).

Quanto à medição do nível de desenvolvimento econômico, certamente devem ser observados os tradicionais índices de desempenho econômico, como produto total, produto per capital e distribuição renda. No entanto, atualmente tem-se dado atenção a outros indicadores de desenvolvimento econômico baseados no trabalho do Nobel de Economia Amartya Sen. Santos (2007) apresenta o conceito de pobreza de Sen como privação de liberdade a partir de um estudo realizado na favela do Vidigal, no Rio de Janeiro. A autora demonstrou que embora os moradores do Vidigal não sejam pobres sob o prisma da renda, 
estes se encontram privados de um conjunto de liberdades disponíveis para os moradores nãofavelados. Como forma de sustentar tal afirmação, Santos utiliza o conceito de funcionamentos e capacitações de Sen. De acordo com o conceito de funcionamentos, é necessário observar dimensões que transcendem o ter - ótica da renda -, considerando a dimensão do ser e fazer, que refletem as realizações consideradas pelos indivíduos como importantes e significativas. Nesse sentido, a "questão central é a qualidade de vida que podemos levar. [...] O valor do padrão de vida repousa na vida, e não na possessão de mercadorias, a qual tem relevância derivada e variável" (SEN ${ }^{8}$ apud SANTOS, 2007, p. 30).

Os funcionamentos representam tudo aquilo que os indivíduos podem ser ou fazer a partir de sua condição econômica e social. A capacitação é a liberdade que um indivíduo tem para escolher sua combinação de funcionamentos, em que o "conjunto de oportunidades de escolha à disposição de uma pessoa constitui o "conjunto capacitário" (SANTOS, 2007, p.30). O conjunto capacitário é análogo ao conjunto orçamentário da teoria microeconômica, refletindo "no espaço de funcionamentos, a liberdade da pessoa para escolher dentre vidas possíveis" (SEN" apud SANTOS, 2007, p. 31).

Sen reconhece que mais renda resulta em mais oportunidades de escolha, no entanto, a renda não é o único condicionante da liberdade para escolher - há uma série de fatores de ordem não econômica que influenciam a liberdade de escolha dos indivíduos como, por exemplo, os serviços de educação e saúde, os direitos políticos e civis, a assistência social, a participação na comunidade, o respeito próprio, o capital social, o acesso ao crédito e à terra, o tipo de emprego (formal ou informal), etc. (SANTOS, 2007, p. 31).

As teorias institucionalistas, bem como as abordagens que consideram as categorias do capital social e da confiança nos permitem iluminar uma dimensão da vida social não tradicionalmente considerada pela teoria econômica, o que representa um avanço no âmbito da Ciência Econômica. Uma característica comum à literatura apresentada nesse artigo, com exceção do conceito de instituição de Douglass North, é que ela se encontra amplamente apoiada em casos empíricos. A pesquisa de Putnam (2000; 2007) tem como base os casos italiano e norte-americano como forma de apresentar e elaborar a categoria do capital social, embora no presente artigo tenha sido mencionado apenas o caso italiano. Locke (2003) tem como objeto de pesquisa a construção da confiança em localidades nas quais esta não se encontra presente, como o Sul italiano e o Nordeste brasileiro. Assim como os trabalhos referidos, este artigo constitui um possível caminho teórico para o estudo de casos concretos.

\footnotetext{
${ }^{8}$ SEN, Amartya. The Standard of living. Cambridge: Cambridge University Press, 1990.

${ }^{9}$ SEM, Amartya. Desigualdade Reexaminada. São Paulo / Rio de Janeiro: Record, 2001.
} 


\section{CONCLUSÃO}

Nesse artigo foram apresentadas teorias institucionalistas e perspectivas sobre capital social e confiança a partir dos trabalhos de alguns autores, como Douglass North, Robert Putnam e Richard Locke.

North fornece uma definição de instituição que compreende não apenas a dimensão formal, mas também a dimensão informal das regras sociais. No âmbito das instituições informais é possível considerar o capital social e a confiança como elementos explicativos do desempenho econômico das sociedades.

Putnam observa, a partir do estudo do caso italiano, que o desempenho institucional está ligado à presença de comunidades cívicas, em que uma cultura de associativismo e confiança mútua entre os cidadãos, bem como de confiança nas instituições, reforça o compromisso social entre os indivíduos e destes com o Estado, gerando um círculo virtuoso de desenvolvimento econômico.

Locke defende a ideia de que a confiança pode ser criada em regiões carentes de redes sociais dotadas de uma cultura de cooperação, nas quais se verifica ainda baixos índices de desenvolvimento econômico e social. A partir das experiências do Sul da Itália com a associação de produtores de mozzarella de búfala e da associação de produtores de uva e manga em Petrolina-juazeiro no Nordeste brasileiro, Locke sustenta a tese de que é possível construir a confiança a partir de uma combinação do auto interesse dos agentes econômicos, com políticas governamentais ativas e mecanismos de autopoliciamento das instituições envolvidas.

Esse artigo objetivou expor algumas ideias e teorias que colaborassem com a construção de categorias explicativas do desenvolvimento econômico e social. Em outras palavras, buscou-se elaborar lentes que nos permitam observar possibilidades de transformação institucional que venham a melhorar as condições de vida das pessoas em regiões pouco desenvolvidas. $\mathrm{O}$ alcance das teorias aqui apresentadas demanda, naturalmente, sua aplicação concreta em estudos de caso específicos.

\section{REFERÊNCIAS}

CHANG, Ha-Joon. Chutando a escada: a estratégia do desenvolvimento em perspectiva histórica. São Paulo: UNESP, 2004. 
COASE, Ronald. The Nature of the Firm. In: COASE, Ronald. The Firm, the Market and the Law. Chicago: The University of Chicago Press, 1990 [1937].

GRANOVETTER, Mark. The Strength of Weak Ties. American Journal of Sociology, n.78, p.1360-1380, 1973.

. The Strength of Weak Ties: a network theory revisited. In: MARSDEN, Peter;

LIN, Lan (eds.) Social Structures and Network Analysis. Newbury Park, CA: Sage Publications, 1982.

LOCKE, Richard. Construindo Confiança. Economica, vol. 3, n.2,set., 2003.

NORTH, Douglass. Structure and Change in Economic History. New York: Norton, 1981. Institutions, Institutional Change and Economic Performance. Cambridge:

Cambridge University Press, 1990.

Understanding the Process of Economic Change. Princeton: Princeton

University Press, 2005a.

Institutions and the Process of Economic Change. Management International

Montréal, vol.9, n.3, 2005b.

PUTNAM, Robert. Bowling alone: the collapse and revival of American community. New York: Simon \& Schuster, 2000.

FGV, 2007.

Comunidade e democracia: a experiência da Itália moderna. Rio Janeiro:

SANTOS, Larissa Martins Neiva. Pobreza como privação de liberdade: um estudo de caso na favela do Vidigal no Rio de Janeiro. Dissertação de Mestrado. Rio de Janeiro, abril, 2007. (Mimeo)

SIMON, Herbert. Bounded Rationality, s.d. (Mimeo). 